\title{
Antibiotic susceptibility of Pseudomonas aeruginosa isolated from different clinical sources

\author{
${ }^{1}$ Fatma Mohamed, ${ }^{2}$ Momen Askoura, ${ }^{3}$ Ghada Shaker \\ Department of Microbiology and Immunology, Faculty of pharmacy, Zagazig University, Egypt \\ ${ }^{1}$ fatmaelfayed@yahoo.com, ${ }^{2}$ momenaskora@yahoo.com, ${ }^{3}$ ghada_shaker61@yahoo.com.
}

Received:1 Nov 2019 /Accepted: 2 Dec 2019 /Published online :30 Dec 2019

\begin{abstract}
Pseudomonas aeruginosa (P. aeruginosa) is a Gram negative opportunistic pathogen which is responsible for many infections in humans. It is the causative agent of nosocomial pneumonia, urinary tract infection, surgical site infections and burn infection. Bacterial resistance to antibiotic is an increasing problems worldwide. Emergence of bacterial resistance to antimicrobials pose a challenge in treating pyogenic infection hence periodical monitoring of bacterial profile and their antibiotic susceptibility pattern is important. In current study, P. aeruginosa isolates obtained from different clinical sources were identified according to traditional biochemical tests. Antibiotic susceptibility testing was performed by the disc diffusion method. Importantly, present results show that $53 \%$ out of $\mathrm{P}$. aeruginosa isolates exhibited multi drug resistance (MDR) pattern. P. aeruginosa isolates showed higher resistance to ciprofloxacin, gatifloxacin and meropenem and intermediate resistance to cefoperazone, cefepime, pipracillin, tobramycin, pipracillin-tazobactam, ceftazidime and azetreonem while Low bacterial resistance was noted against colistin only. The inappropriate use of antibiotics has led to the development of resistant bacteria which led to ineffective antibiotic therapy. Current study suggests applying of strict policies for antibiotic prescription and dispensing.
\end{abstract}

Key words: Pseudomonas aeruginosa, Antimicrobial susceptibility, Antibiotic resistance, Multidrug resistance

\section{INTRODUCTION}

P. aeruginosa is a Gram-negative opportunistic pathogen. It is a ubiquitous bacterium that is found and isolated from various environments including plants, animals, soil and humans (Filiatrault $\boldsymbol{e t} \boldsymbol{a l}$. 2006). P. aeruginosa accounts for $10-15 \%$ of nosocomial infections worldwide (Strateva and Yordanov 2009) and is considered the third most-common organism associated with hospital-acquired infections such as urinary catheter-associated infections ventilator-associated pneumonia as well as blood, burn and wound infections. In addition, $P$. aeruginosa is the causative agent of a wide variety of life-threatening infections, particularly in immune compromised patients (Moreau-Marquis $\boldsymbol{e t}$ al. 2008; Stover et al. 2000).
Bacterial resistance to antibiotics is a global health problem that limits the therapeutic options. $P$. aeruginosa develops resistance against almost all antibiotics by several mechanisms like, multi-drug resistance efflux pumps, resistance genes, biofilm formation, aminoglycoside modifying enzymes and mutations in different chromosomal genes. Further more exposure to broad spectrum antibiotics and patient to patient spread have added the rapid increase in the isolation of rapid strains (Gill et al. 2011). This study aims to investigate the antimicrobial resistance pattern of $P$. aeruginosa isolated from different sources such as urine, sputum, burn and wound. 
Zagazig J. Pharm. Sci. Dec, 2019

Vol. 28, Issue 2, pp. 10 - 17

\section{Materials and Methods}

\section{Bacterial isolation and identification}

A total of 300 clinical specimens were collected from patients admitted to Zagazig University Hospital and from Al-Ahrar Hospital in Zagazig from different sources. Handling of specimens and isolation were performed following the standard microbiological procedures. Samples were cultured on nutrient agar (LabM, UK) and incubated overnight at $37^{\circ} \mathrm{C}$. Colonies appeared on nutrient agar were further examined by Gram-stain; only Gramnegative isolates with green color on nutrient agar were further sub cultured overnight at $37^{\circ} \mathrm{C}$ on selective medium cetrimide agar (Lab M, UK). Pure colonies on cetrimide agar were further identified by biochemical tests including oxidase test, oxidationfermentation test $(\mathrm{O} / \mathrm{F})$, gelatin liquefaction, motility, growth at $42^{\circ} \mathrm{C}$ and growth on triple sugar iron (TSI) agar (Winn et al. 2006).

\section{Antibiotic susceptibility testing of bacterial isolates}

The antibiotic susceptibility test was performed using Kirby-Bauer disc diffusion method (Bauer et al. 1966). The antimicrobial discs were purchased from Oxoid (Hampshire, England) and include; piperacillin (PRL, 100 $\mu \mathrm{g}$ ), piperacillintazobactam (TPZ, 110 $10 \mathrm{~g}$ ), cefoperazone

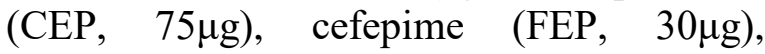
ceftazidime (CAZ, 30 $\mu$ g), ciprofloxacin (CIP, $5 \mu \mathrm{g})$, gentamycin $(\mathrm{CN}, 10 \mu \mathrm{g})$, colistin sulfate $(\mathrm{CT}, 10 \mu \mathrm{g})$, aztreonam (ATM, 30 $\mathrm{g}$ ), meropenem (Mem,10 $\mu \mathrm{g}$ ),tobtamycin(TOB,

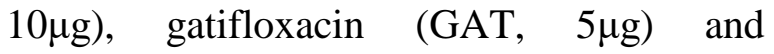
amikacin (AK, 30 $\mathrm{g}$ ). Bacterial suspensions were prepared from overnight cultures on Muller-Hinton agar (Oxoid, Hampshire, England). Suspensions densities were adjusted to $0.5 \mathrm{McFarland}$ standard that correspond to approximately $\left(1.5 \times 10^{8}\right.$ $\mathrm{CFU} / \mathrm{mL}$ ). The surface of Muller-Hinton agar plate was inoculated with suspensions using sterile cotton swabs. The plates were dried before applying the antibiotic discs and incubated overnight at $37^{\circ} \mathrm{C}$. The diameters of inhibition zones around the discs were measured. The results were interpreted according to Clinical Laboratory Standards Institute guidelines (CLSI, 2018).

\section{RESULTS}

\section{Isolation and identification of $P$. aeruginosa}

$P$. aeruginosa was isolated and identified in $33.3 \%$ of clinical samples. One hundred $P$. aeruginosa isolates were recovered from different sources which are shown in (Table 1). $P$. aeruginosa was identified as Gramnegative rods, lactose non-fermenting, appearing as large colonies with characteristic grape-like odor and greenish pigment (pyocyanin) on nutrient agar in addition to pyocyanin non-producing colonies on cetrimide agar. Suspected as $P$. aeruginosa bacteria were collected and further identified based on biochemical characteristics as shown in (Table 2) (macFaddin 2000). 
Table 1: Sources of P.aeruginosa isolates.

\begin{tabular}{ll}
\hline Source & No. of P. aeruginosa isolates \\
\hline Burn & 25 \\
\hline Urine samples & 27 \\
\hline Endotracheal aspirates & 29 \\
\hline Wound \& pus & 11 \\
\hline Eye & 5 \\
\hline Ear & 3 \\
\hline Total Number & 100 \\
\hline Table 2. Biochemical characteristics of clinical P. aeruginosa isolates
\end{tabular}

Biochemical test $\quad$ Result

\begin{tabular}{ll}
\hline Oxidase & $+^{*}$ \\
Oxidation-Fermentation test $(\mathbf{O} / \mathbf{F})$ & $\mathrm{O}^{+} / \mathrm{F}^{* * *}$
\end{tabular}

\begin{tabular}{ll} 
Gelatin liquefaction & $+* * *$ \\
\hline Motility & Motile
\end{tabular}

\begin{tabular}{ll} 
Growth at $42^{\circ} \mathrm{C}$ & + \\
\hline Growth on triple sugar iron (TSI) agar & $\mathrm{K} / \mathrm{K}^{* * * *}$ \\
\hline
\end{tabular}

\footnotetext{
*Color change to violet within 15-30 second

**Only aerobic tube $(O)$ turned yellow the fermentative tube $(F)$ remain green

*** Partial or total liquefaction of the inoculated tube (control tube must be solid)

**** K: alkaline slant/ $K$ : alkaline butt reaction,
}

\section{Antibiotic Susceptibility Test:}

The antibiotic resistance profile of $P$. aeruginosa showed varying antibiotic resistance patterns to different antibiotics (figure1). High bacterial resistance was found against ciprofloxacin, and gatifloxacin (63\% each), gentamycin $(62 \%)$ and meropenem $(60 \%)$. Intermediate bacterial resistance was found against cefoperazone, cefepime, pipracillin, and tobramycin (57\% each), amikacin (56\%), pipracillintazobactam, ceftazidime and azetreonam (53\%,46\%, and 34\% respectively). Low bacterial resistance was noted only with colistin (7\%). Twenty isolates were found to be susceptible to all tested antibiotics $(20 \%)$ 
and only two isolates was pan-drug resistant being resistant to all tested antibiotics. The antibiotic susceptibility testing showed that 53 out of $100 P$. aeruginosa isolates in this study were MDR (non-susceptible to at least one agent in three or more antimicrobial categories) as shown in Table 3.

Figure (1): Percentage of isolates resistance against tested antibiotics.

Abbreviations; amikacin (AK), gentamycin $(\mathrm{CN})$,

ciprofloxacin (CIP), meropinem (M EM), pipracillin (PRL), cefoperazone (CEP), piperacillin/tazobactam (TPZ), cefepime (FEP), ceftazidime (CAZ), Aztreonam (ATM), colistin (CT), Tobramycin (TOB), Gatifloxacin (GAT)

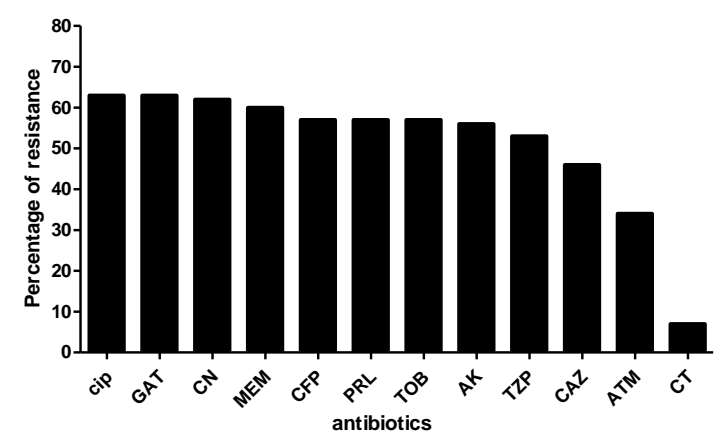

Table 3: Frequency of multidrug resistant isolates of $P$. aeruginosa

\begin{tabular}{|l|l|l|}
\hline $\begin{array}{l}\text { Number of } \\
\text { resistant } \\
\text { isolates }\end{array}$ & $\begin{array}{l}\text { Number of } \\
\text { Antibiotic } \\
\text { classes }\end{array}$ & $\begin{array}{l}\text { Classes of } \\
\text { antibiotics }\end{array}$ \\
\hline 4 & 4 & $\begin{array}{l}\text { B-lactams, } \\
\text { aminoglycosides, } \\
\text { fluoroquinolones } \\
\text { and lipopeptide }\end{array}$ \\
\hline \multirow{2}{*}{47} & \multirow{2}{*}{3} & $\begin{array}{l}\text { B-lactams, } \\
\text { aminoglycosides } \\
\text { and } \\
\text { fluoroqinolones. }\end{array}$ \\
\cline { 3 - 4 } & & $\begin{array}{l}\text { B- } \\
\text { lactams,lipopeptide } \\
\text { and } \\
\text { fluoroqinolones. }\end{array}$ \\
\hline
\end{tabular}

\section{DISCUSSION:}

$P$. aeruginosa is a significant opportunistic pathogen that causes many fatal infections in persons with serious medical conditions such as immunocompromised persons (Gellatly and Hancock 2013). $P$. aeruginosa is considered to be very dangerous because it can easily colonize epithelial surfaces, weaken host defenses, induce systemic toxicity and is associated with elevated morbidity and mortality rates (Juayang et al. 2017). Improper use of antimicrobials resulted in the development of MDR strains which are quite hard to be treated due to their higher resistance to various antibiotics (Lister et al. 2009). The present study was performed to investigate the antimicrobial resistance of $P$. aeruginosa isolated from different sources.

The prevalence of MDR isolates among the overall collected isolates was 53/100 $(53 \%)$. This was similar to a previous study that reported a prevalence rate of $52 \%$ (Mahmoud et al. 2013). Other global studies exhibited lower MDR rates; $5.9 \%$ in Canada (Zhanel et al. 2010) \& Germany (Narten et al. 2012). The obtained results may be attributed to numerous factors that participated in the spread of MDR isolates in Egypt; primarily the increased disaster of antibiotic misuse without proper prescriptions (Daniel et al., 2015). This elevated MDR rate in Egypt in comparison to other countries gives us an alarm to the necessity of the application of rigorous antibiotic prescription strategies. The variability observed in the distribution of MDR $P$. aeruginosa isolates, the resistance rates and susceptibility profile against different antibiotics between the present study and the other studies could be attributed to the variation of the antibiotics usage policy applied in each country (Bekele et al., 2015).

In current study, the resistance rates against different antibiotics were variable. The overall 100 isolates showed highest resistance against fluroqinolones (ciprofloxacin, gatifloxacin (63\% each), 
the aminoglycosides gentamycin (62\%), followed by carbapenem (meropenem; $60 \%$ ). The resistance rate of ciprofloxacin in our study (63\%) was in accordance with (Senthamarai 2014) who reported (61.53\%). While another study showed low resistance (25\%) by (Ogbolu et al., 2008). The difference in the rate of ciprofloxacin resistance is usually related to the frequency of use of fluoroquinolones and availability of oral doses.

Aminoglycosides are significant members of broad spectrum antibiotics. They act mainly by inhibiting protein synthesis and breaking bacterial cell membrane (Shakil et al. 2008). This study showed the resistance rate of gentamycin $(62 \%)$ was higher than that of amikacin and tobramycin (56\% for each).These findings were in agreement with was a previous study by (Raytaker et al. (2017) that showed higher resistance rate to gentamycin $(57.8 \%)$ than that of amikacin (35\%). On other hand, another study by Khan et al. (2014) showed that amikacin was the most effective antibiotic with resistance rate $(10 \%)$. Resistance of clinical isolates to aminoglycoside antibiotics was found to vary with specific drug, the microorganism, its mechanism of resistance, the geographic area and many other factors (Vakulenko and Mobashery 2003).

Carbapenems are considered the most significant group of antibiotics against MDR $P$. aeruginosa but the development of carbapenems resistance is becoming a challenge for health care professionals and has limited the therapeutic options. Sufficient measures are required to prevent the spread of carbapenemase encoding gene (Rodríguez-Martínez et al. 2009). The current study demonstrated that $60 \% P$. aeruginosa were resistant to carbapenem antibiotic (meropenem). This finding was in agreement with that reported by (Rodríguez-Martínez et al. 2009, and Khan et al. 2014) where resistance rates were found to be $60 \%$ and $87 \%$; respectively. It is very obvious that efficacy of this particular antibiotic is declining. The reason for the high resistance to meropenem in our study is that the drug is commonly used in the treatment of many infections. This warrants a need to de-escalate therapy based on cultures, as it is not just Pseudomonas that will be resistant, but many members of Enterobacteriaceae would be resistant, including emergence of carbapenem-resistant Enterobacteriaceae (Khan and Faiz 2016).

In the present study, increased bacterial resistance to $\beta$-lactam antibiotics has been detected. The high resistance to $\beta$-lactam in nosocomial $P$. aeruginosa has become a serious threat particularly against third and fourth generation cephalosporins. There are many molecular mechanisms to develop resistance against these antibiotics; including generation of extended-spectrum betalactamases (ESBL), incorporation of bla genes in integrons and inability of porin genes to enhance their expression level and/or alteration of antibiotic target sites (Pfeifer et al. 2010). P. aeruginosa isolates were resistant to the expanded spectrum penicillin, pipracillin (57\%). Similar result founded in a recent study by Pokharel $\boldsymbol{e t} \boldsymbol{a l}$. (2019) showing resistance rate of $56.5 \%$. However lower resistance rate $(28 \%)$ was reported by Abbas et al. (2018). The isolates were also resistant to the pipracillinTazobactam combination $(53 \%)$ which was slightly less than the $56.6 \%$ that reported by Khan et al., (2014), while it was different from the low resistance $(4.9 \%)$ reported by Khan and Faiz ( 2016).

For the $3^{\text {rd }} \& 4^{\text {th }}$ generation cephalosporins, $P$. aeruginosa isolates exhibited resistance rate of $57 \%$ to each cefoperazone and cefipime. This result is less than that reported by (Mahmoud et al. 2013) who showed a resistance rates of $73.3 \%$ and $98.2 \%$; respectively. While Khan and Faiz (2016) showed low resistance rate for cefepime $(8.3 \%)$.

In the present study, $P$. aeruginosa isolates showed resistance rate of $46 \%$ to 
ceftazidime. This result is higher than that of Khan and Faiz (2016) who reported resistance rate $14 \%$ while Mahmoud $\boldsymbol{e t}$ al. (2013) and Pokharel et al. (2019) reported high resistance rate of $91.2 \%$ and $63 \%$; respectively. For the monobactam, azetronam, the isolates exhibited low resistance rate (34\%), Mahmoud et al. (2013) showed high resistance rate $(82.5 \%)$.

Our results showed that colistin was the most effective antibiotic against $P$. aeruginosa with resistance rate of $(7 \%)$. This result is comparable with Afifi et al.(2013), who reported resistance rate of $3 \%$ while $0 \%$ resistance was reported by Pokharel et al. (2019). This study indicates that colistin is an efficient therapy against MDR $P$. aeruginosa isolates followed by aztreonem among all tested antibiotics. It is very obvious that efficacy of particular antibiotic is declining as fluroquinolones

\section{REFERENCES}

Abbas HA, El-Ganiny AM, Kamel HA. (2018). Phenotypic and genotypic detection of antibiotic resistance of Pseudomonas aeruginosa isolated from urinary tract infections. African health sciences. 18(1):11-21.

Afifi MM, Suelam I, Soliman M, El-Gohary M. (2013). Prevalence and antimicrobial susceptibility pattern of Pseudomonas aeruginosa isolated from environmental and clinical samples in upper egypt. The International Journal of Biological and Chemical Sciences. 7:47-57.

Bauer A, Kirby W, Sherris JC, Turck M. (1966). Antibiotic susceptibility testing by a standardized single disk method. American journal of clinical pathology. 45(4_ts):493-496.

Bekele, T.; Tesfaye, A.; Sewunet, T. and Waktola, H.D. (2015): Pseudomonas aeruginosa Isolates and Their Antimicrobial Susceptibility Pattern among Catheterized Patients at Jimma University Teaching Hospital, Jimma, and carbapenems in treatment of $P$. aeruginosa infections.

\section{CONCLUSION:}

The emergence of MDR $P$. aeruginosa and its continual spread is out of debate. Antibacterial research is not sufficient to keep pace with the clinical challenges of MDR bacterial crises. Failure of antibiotic treatment could result from misuse and abuse of antibiotics in addition prescription of antibiotics without performing susceptibility testing beside the extensive use of broad spectrum antibiotics. New therapeutic agents with maximum efficacy, lesser toxicity and cost effective in nature are urgently needed to overcome the problem of antibiotic resistance. In addition, strict laws regarding antibiotic policies should be constructed to limit the unnecessary use of antibiotics so that spread of multidrug resistance can be avoided.

Ethiopia. BMC Research Notes. 8: 488491.

CLSI C (2018). CLSI Performance Standards for Antimicrobial Susceptibility Testing. Clinical and Laboratory Standards Institute.

Daniel, S.A.; Shawky, M.S.; Omar, H.M.G.; Hamida M. Abou-Shleib, H.M. and El-Nakeeb, M.A. (2015): Antibiotic Resistance and Its Association with Biocide Susceptibilities among Microbial Isolates in an Egyptian Hospital. International Arab Journal of Antimicrobial. Agents. 4(4): 1-11.

Filiatrault MJ, Picardo KF, Ngai H, Passador L, Iglewski BH. (2006). Identification of Pseudomonas aeruginosa genes involved in virulence and anaerobic growth. Infection and immunity. 74(7):4237-4245.

Gellatly SL, Hancock RE. (2013). Pseudomonas aeruginosa: New insights into pathogenesis and host defenses. Pathogens and disease. 67(3):159-173. 
Gill MM, Usman J, Kaleem F, Hassan A, Khalid A, Anjum R, Fahim Q. (2011). Frequency and antibiogram of multidrug resistant pseudomonas aeruginosa. journal college physicians surgeons pakistan. 21(9):531-534.

Juayang A, Lim J, Bonifacio A, Lambot A, Millan S, Sevilla V, Sy J, Villanueva P, Grajales C, Gallega C. (2017). Fiveyear antimicrobial susceptibility of pseudomonas aeruginosa from a local tertiary hospital in bacolod city, philippines. Tropical medicine and infectious disease. 2(3):28.

Khan F, Khan A, Kazmi SU. (2014). Prevalence and susceptibility pattern of multi drug resistant clinical isolates of pseudomonas aeruginosa in karachi. Pakistan journal of medical sciences. 30(5):951.

Khan MA, Faiz A. (2016). Antimicrobial resistance patterns of pseudomonas aeruginosa in tertiary care hospitals of makkah and jeddah. Annals of Saudi medicine. 36(1):23-28.

Lister PD, Wolter DJ, Hanson ND. (2009). Antibacterial-resistant pseudomonas aeruginosa: Clinical impact and complex regulation of chromosomally encoded resistance mechanisms. Clinical microbiology reviews. 22(4):582-610.

MacFaddin J. (2000). Biochemical tests for identification of medical bacteria 3rd edition lippincott williams and williams. USA.

Mahmoud AB, Zahran WA, Hindawi GR, Labib AZ, Galal R. (2013). Prevalence of multidrug-resistant pseudomonas aeruginosa in patients with nosocomial infections at a university hospital in egypt, with special reference to typing methods. Journal of Virology Microbiology science. 13:165-159.

Moreau-Marquis S, Bomberger JM, Anderson GG, Swiatecka-Urban A, Ye S, O'Toole GA, Stanton BA.
(2008). The $\delta$ f508-cftr mutation results in increased biofilm formation by pseudomonas aeruginosa by increasing iron availability. American Journal of Physiology-Lung Cellular and Molecular Physiology. 295(1):L25-L37.

Narten M, Rosin N, Schobert M, Tielen P. (2012). Susceptibility of pseudomonas aeruginosa urinary tract isolates and influence of urinary tract conditions on antibiotic tolerance. Current microbiology. 64(1):7-16.

Ogbolu D, Ogunledun A, Adebiyi O, Daini O, Alli A (2008). Antibiotic susceptibility patterns of Pseudomonas aeruginosa to available antipseudomonal drugs in Ibadan, Nigeria. African journal of medicine and medical sciences 37(4): 339-344

Pfeifer Y, Cullik A, Witte W. (2010). Resistance to cephalosporins and carbapenems in gram-negative bacterial pathogens. International Journal of Medical Microbiology. 300(6):371-379.

Pokharel K, Dawadi BR, Bhatt CP, Gupte S. (2019). Prevalence of pseudomonas aeruginosa and its antibiotic sensitivity pattern. Journal of Nepal Health Research Council. 17(1):109-113.

Raytaker N, Choudari M, Das S. (2017). Antibiotic profilling of pseudomonas aeruginosa isolates from pus sample of rural tertiary care hospital of western mahanashtra, loni, india. International Journal of Research in Medical Sciences. 5(7):3076-3081.

Rodríguez-Martínez J-M, Poirel L, Nordmann P. (2009). Molecular epidemiology and mechanisms of carbapenem resistance in pseudomonas aeruginosa. Antimicrobial agents and chemotherapy. 53(11):4783-4788.

Senthamarai S. (2014). Resistance pattern of pseudomonas aeruginosa in a tertiary care hospital of kanchipuram, tamilnadu, india. Journal of clinical and diagnostic research: JCDR. 8(5):DC30. 
Shakil S, Khan R, Zarrilli R, Khan AU. (2008). Aminoglycosides versus bacteria-a description of the action, resistance mechanism, and nosocomial battleground. Journal of biomedical science. 15(1):5-14.

Stover C, Pham X, Erwin A, Mizoguchi S, Warrener P, Hickey M, Brinkman F, Hufnagle W, Kowalik D, Lagrou M. (2000). Complete genome sequence of pseudomonas aeruginosa PAO1, an opportunistic pathogen. Nature. 406(6799):959.

Strateva T, Yordanov D. (2009). Pseudomonas aeruginosa-a phenomenon of bacterial resistance. Journal of medical microbiology. 58(9):1133-1148.
Vakulenko SB, Mobashery S. (2003). Versatility of aminoglycosides and prospects for their future. Clinical microbiology reviews. 16(3):430-450.

Winn W, Allen S, Janda W, Koneman E, Procop G, Schreckenberger P, Woods G. (2006). The non-fermentative gramnegative bacilli. Color atlas and textbook of diagnostic microbiology. 6 .

Zhanel GG, DeCorby M, Adam H, Mulvey MR, McCracken M, Lagacé-Wiens P, Nichol KA, Wierzbowski A, Baudry PJ, Tailor F. (2010). Prevalence of antimicrobial-resistant pathogens in canadian hospitals: Results of the canadian ward surveillance study (canward 2008). Antimicrobial agents and Chemotherapy. 54(11):4684-4693.

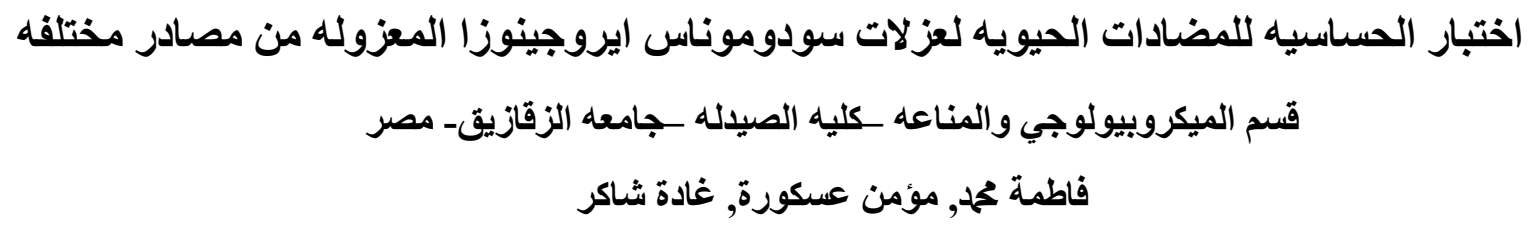

تم تجميع مئه عينه من بكتيريا السودوموناس ايروجينوزا. وتم التعرف على الته عزلات التئه السودوموناس ايروجينوزا وفقا

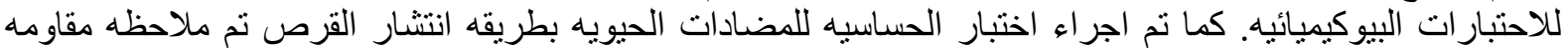

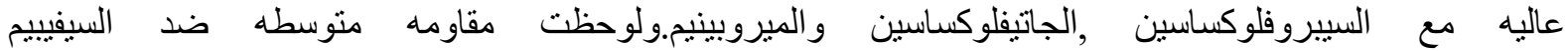

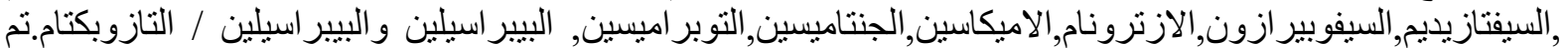

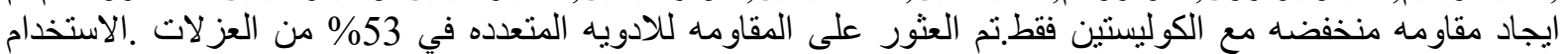

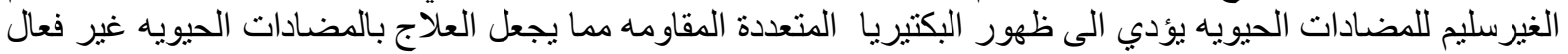

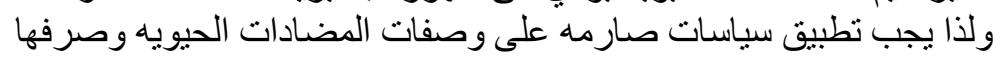

